\title{
14 \\ Using Interteaching to Enhance Student Engagement and Learning
}

\author{
Alan Scoboria, Fuschia M. Sirois, \& Antonio Pascual-Leone \\ University of Windsor
}

In this paper, we describe our experience with a recently devised teaching method termed interteaching (Boyce \& Hineline, 2002). This educational approach provides a rich rehearsal of material, and emphasizes student engagement, peer discussion, and student/instructor interaction. We describe the method, provide pragmatic tips for implementation in the classroom, review empirical evidence, and discuss advantages and disadvantages.

\section{Introducing Interteaching}

T he less than adequate characteristics of traditional lecture-based educational methods are well established. Research indicates that lecture alone leads to student passivity, does little to promote retention of learned material, discourages interaction between students and instructors, and makes it difficult for instructors to obtain timely feedback about student understanding. Research on educational outcomes shows that effective teaching typically accomplishes the opposite: promotes student engagement, furthers long-term retention via rehearsal, increases interaction among students and instructors, results in useful feedback from students, and is generally enjoyed by students and instructors (McKeachie, 2002).

Interteaching is an educational method developed by Boyce $\&$ Hineline (2002) to adapt Keller's
(1968) Personalized System of Instruction (PSI) into a form more palatable to university course formats. Keller developed PSI to address what he perceived as undesirable characteristics of lecture-based teaching. To address these limitations, he applied operant conditioning principles in the university classroom. In PSI, course material is divided into units which are sequenced by order of difficulty. Students study one unit at a time until they demonstrate mastery of the material on an exam. Students, therefore, complete the units at their own pace. During a PSI course, optional lectures may be given, primarily to enhance student motivation. Proctors, typically graduates of the course, provide tutoring and mark assignments. The instructor's primary roles are to structure the course, supervise proctors, and construct exams. 
Rather than articulating information to students via lecture, the instructor acts as a facilitator of learning.

Research has generally supported the benefits of PSI. For example, Lloyd \& Lloyd (1992) report that students instructed via PSI outperformed those taught using other methods (e.g., traditional lecture and computer-based instruction) on final exams. Despite such advantages, the use of PSI has decreased since its inception. Eyre (2007) describes several reasons for this trend. First, many instructors find PSI cumbersome in practice. Indeed, preparing courses, developing multiple tests, and training and supervising proctors can be timely. Second, teaching to mastery tends to lead to uniformly high grades. Third, the self-paced nature of PSI makes the provision of the course material to all students challenging, and is also associated with student procrastination. Finally, levels of interaction with students are low, and instructors often find the lack of social exchange unrewarding.

Interteaching resolves these difficulties by employing many of the key principles of PSI with several important revisions, and by working in the context of a common university course framework. Similar to PSI, responsibility for initial engagement with course material is transferred to students. Courses are segmented into units, and students study material on their own. The instructor designs the course to facilitate student engagement with material, and pays particular attention to links between readings, class discussion, and exam questions.

Interteaching differs from PSI in several important ways. Self-pacing is eliminated, and the goal of mastery is de-emphasized to encourage student engagement and provide multiple exposures to material. This is accomplished by borrowing techniques from Reciprocal Peer Tutoring (RPT; Griffin \& Griffin, 1998) and cooperative learning (Halpern, 2004). These approaches share the assumption that one effective manner of learning is to teach others. For example, in the RPT model, students develop questions that they use to quiz one another with before exams. Interteaching places peer-to-peer discussion of course material in a central role. It is the exchange between well prepared peers, which Boyce and Hineline (2002) emphasize when defining interteaching as, "[a] mutually probing, mutually informing con- versation between two people.” (p. 215)

Interteaching also provides a more visible role for instructors than PSI, for example, engagement with students during class discussions, and the provision of 'just-in-time' lectures which address student questions about the material. Thus, in interteaching, the instructor's roles are: to structure and guide learning, promote student engagement, facilitate peer discussion, and clarify challenging information (Saville, 2006).

\section{Interteaching Methods}

The procedures of interteaching involve a number of steps. We list these briefly at this point, and expand on each below. Prior to the course, the instructor selects readings, and develops a preparation guide for each class. The method is introduced to students at the start of the course, and students prepare for class by reading and developing answers to the questions on the guide. In class, students discuss the preparation guide in pairs, while the instructor circulates to answer questions. After discussion, students complete an interteaching report, to provide feedback to the instructor. Finally, the instructor prepares a clarifying lecture based on this feedback, which is given at the beginning of the next class.

\section{Course preparation}

The course begins with the selection of readings and the construction of preparation guides. These guides consist of assigned readings and a series of questions that challenge students to comprehend key course material and direct them to important information. These guides are a central feature of interteaching. We have found that well-constructed guides can promote excellent in-class discussion and result in enhanced student interest. On the other hand, poorly constructed guides can inhibit discussion. Thus, the guide carries considerable weight, and without it, the remainder of the procedures tend to fall short.

Preparing excellent guides requires careful selection of readings and balancing of types of questions, so that students are reasonably challenged and 
different types of processing information are encouraged. Successful guides contain a mixture of questions that probe factual knowledge, and others that promote transformation of information via critical and analytic reasoning. For example, we find that including a limited number of questions, which cannot be directly answered from the readings but can be addressed via analytical thought, is a powerful teaching tool.

\section{Introducing interteaching}

At the start of a course, the instructor introduces the method. Some students are reluctant to engage in a new style of learning, and so the instructor must 'sell' the value of the method. This might include citing supportive empirical evidence, discussion of the rationale for the method, and noting that students frequently report the approach to be enjoyable than lecture alone. As with all teaching, it is important to develop a supportive culture in the classroom. Perhaps not surprising, we find that instructor enthusiasm for the approach goes a long way in motivating students to participate.

\section{Student preparation}

We encourage our students to complete the readings and arrive to class with notes to answer discussion questions. Some students follow this advice, while others prefer to come with answers to questions fully prepared. We find that it is useful to provide students with advice as to what constitutes adequate preparation, as well as to describe several different preparation strategies. We believe this helps students adapt interteaching to fit with their preferred learning styles. The fact that our students raise concerns about their level of preparation suggests that they find the method engaging.

\section{In-class}

By the time students arrive for class, they have already read the assigned materials and have processed it at a level sufficient to comprehend the questions on the guide. Class sessions begin with a focussed clarifying lecture about the material from the prior class (see below). The majority of the class is devoted to discus- sion of new material (two thirds to three quarters of available time is recommended). Students work together in pairs to discuss and answer the questions on the guide. An important component of the model is that students discuss with a different partner in each class. This serves several purposes: to maintain accountability to future partners, discourage interaction only with friends, and reduce social loafing. In practice, we vary the size of groups and the frequency of switching groups. Smaller groups (four or fewer) and switching with reasonable frequency (every two to three sessions) is important when facilitating quality discussions.

When introducing the method and throughout the course, students should be encouraged to pay attention to similarities and differences in their and their peers approaches to questions. This type of interchange enhances students' awareness of the quality of their preparation. Students also benefit from being reminded that teaching information to others, even those who appear underprepared, is a way of enhancing their own learning.

As discussion progresses, the instructor circulates to answer questions, provoke interaction, and observe student comprehension. The instructor can intervene immediately when students are off track or struggling with material. We find that circulating in this manner promotes lively, engaged, and enjoyable interactions with our students.

While not a component of the original interteaching model, our students have expressed appreciation for brief introductions to novel topics prior to discussion. Hence, we frequently provide a five to ten minute introduction prior to discussion. We call this addition to the model an 'orienting lecture.' We find this a useful opportunity to focus student's thinking prior to discussion.

\section{Interteaching reports}

Following discussion, each student completes an interteaching report. Students name their discussion partner(s), and assess how well the discussion went. Evaluating the quality of the exchange shows students the importance of preparation and discussion. More important, students can note any difficult questions, and specifically articulate the problem. This report 
provides an alternate way to convey thoughts to the instructor, and is vital for communicating with students who may otherwise be reluctant to discuss concerns verbally (e.g., due to embarrassment, shyness, or lack of willingness to admit ignorance).

\section{Clarifying lectures}

Based on the feedback obtained from the reports and while circulating, the instructor prepares a clarifying lecture. This presentation is designed to facilitate understanding of challenging material. As noted above, the clarifying lecture occurs at the start of the subsequent class session. As this lecture flows from student input, students are likely to find it both relevant and interesting.

\section{Evaluation}

Boyce and Hineline (2002) recommend a clear relationship between preparation guide questions and test items. We also inform our students that they are responsible for material (from readings, class discussion, or lecture) not covered explicitly in guides.

\section{Evidence for the Effectiveness of Interteaching}

Research supports the effectiveness of interteaching. A laboratory-based study demonstrated that interteaching results in superior test performance relative to lecture, reading, or control groups (Saville \& Zinn, 2005). Another study conducted in smaller university classes (12 to 25), found that interteaching resulted in an average $6.5 \%$ gain on cumulative final examination scores relative to lecture (Saville, Zinn, Neef, et al., 2006). A third study in which preparation guides plus in-class discussion was contrasted with the provision of guides alone demonstrated that the discussion component of the model is key to producing learning gains (Saville, 2006).

Two of the current authors (Scoboria \& Pascual-Leone, 2008) recently studied an adaptation of interteaching in two large undergraduate abnormal psychology courses (enrolments 60 and 120). We found that grades on a standardized writing assign- ment were significantly greater following interteaching as compared with two prior offerings of the same course. Furthermore, frequency of attendance at discussion sessions showed positive relationships with performance on writing assignments, and weaker relationships with exam grades, after controlling for academic average (GPA) and student motivation for the teaching method.

Perhaps most notable, in all of the studies cited in this section, a majority of students expressed a preference for interteaching over straight lecture.

\section{Advantages of Interteaching}

We believe that interteaching provides a number of advantages over lecture-based instruction. Interteaching promotes active learning. Students must read, prepare answers, hold discussions, and listen to relevant lectures. All of this increases exposure to material, timeon-task, and individual engagement. Students must not only understand the material, but also be able to help their peers. Such transformations of knowledge help to crystallize the information in memory. An added benefit is the practice of communication skills. Interteaching creates a cooperative learning environment, which relies in part on mutual social reinforcement by peers and the instructor.

By the time students write exams, they have touched on the material multiple times and in a variety of modes. Completed guides also serve as excellent study notes. Students have multiple resources to turn to for studying, including readings, discussion notes, clarifying lecture notes, and peers with whom they hold discussions.

Finally, the method is self-correcting. Instructors and students can receive immediate feedback about topics which are not well understood.

\section{Disadvantages of Interteaching}

Interteaching is not without drawbacks. Initial preparation for interteaching-based courses can be somewhat more rigorous than preparing for lecture. Instructors must take the time to select (or develop) reading ma- 
terials, design preparation guides and ensure that they are reasonably linked to evaluation methods. Instructors must tailor clarifying lectures as the course progresses. In our experience, the time required is similar to or less than that which is required to prepare for straight lectures. Furthermore, we find that many of the questions which arise can be anticipated based on the guide questions. Hence, we frequently prepare the framework for clarifying lectures in advance, and tailor them to specific student questions as needed. Since clarifying lectures are fairly short, adapting them to student questions is quite manageable. Knowing that the material is immediately relevant to student interest is worth this additional expenditure of effort.

Student engagement is an essential component of this approach. We observed several types of student attitudes that run counter to the method. Some students come to class with the guide completed, and an attitude that their work is already done. Other students express a desire to work alone or with the same partner each class. It is therefore important to convey to students the advantages of engagement. For example, the benefits of explaining material to others and the advantages of working with others to correct errors can be emphasized.

Finally, with the class-to-class cycle of preparation and discussion, there tends to be burnout later in the term. Hence, effort put into preparation and discussion begins to wane. Planning a variety of other didactic tasks throughout the course may thus prove helpful.

\section{Summary}

Interteaching is a theoretically-based and empiricallytested educational method which addresses many of the limitations of lecture-based and behaviourallyinformed didactic methods. Interteaching addresses a number of challenges inherent to university teaching: motivating student interest, encouraging repeated exposure to and deep processing of material, promoting meaningful interaction between peers and instructors, and potentiating the development of knowledge acquisition skills, to name a few. Instructors who are seeking a teaching method which achieves these vari- ous goals may be interested in experimenting with the method themselves.

\section{Authors' Note}

Direct correspondence to any of the authors at: Department of Psychology, 401 Sunset, Windsor, ON, Canada, N9B 3P4; scoboria@uwindsor.ca, fsirois@ uwindsor.ca, apl@uwindsor.ca. This work was completed while the authors held support from the University of Windsor Centre for Teaching and Learning, Centered on Learning Innovation Fund.

\section{References}

Boyce, T.E., \& Hineline, P.N. (2002). Interteaching: A strategy for enhancing the userfriendliness of behavioural arrangements in the college classroom. The Behavior Analyst, 25, 215-226.

Eyre, H.L. (2007). Keller's personalized system of instruction: Was it a fleeting fancy or is there a revival on the horizon? The Behavior Analyst Today, 8(3), 317-324.

Keller, F.S. (1968). Good-bye teacher... Journal of Applied Behavior Analysis, 1, 79-89.

Halpern, D.F. (2004). Creating cooperative learning environments. In B. Perlman, L.I. McCann, \& S.H. McFadden (Eds.), Lessons learned: Practical advice for the teaching of psychology (pp. 149-155). Washington DC, American Psychological Society.

Griffin, M.M. \& Griffin, B.W. (1998). An investigation of the effects of reciprocal peer tutoring on achievement, self-efficacy, and test anxiety. Contemporary Educational Psychology, 23, 298-311.

Lloyd, K.E., \& Lloyd, M.E. (1992). Behavior analysis and technology in higher education. 
In R. P. West \& L. A. Hamerlynck (Eds.), Designs for excellence in education: The legacy of B. F. Skinner (pp. 147-160). Longmont, CO: Sopris West.

McKeachie, W.J. (2002). McKeachie's teaching tips: Strategies, research, and theory for college and university teachers (11th ed.). Boston: Houghton-Mifflin.

Saville, B.K. (2006). From sage on the stage to guide on the side: An alternative approach to teaching research methods. Paper presented at the Annual Teaching Institute, Association for Psychological Science, New York, NY.

Saville, B.K., \& Zinn, T.E. (2005). Interteaching versus traditional methods of instruction: A preliminary analysis. Teaching of Psychology, 32(3), 161-163.

Saville, B.K., Zinn, T.E., Neef, N.A., Van Norman, R., \& Ferreri, S.J. (2006). A comparison of interteaching and lecture in the college classroom. Journal of Applied Behavior Analysis, 39(1), 4961.

Scoboria, A., \& Pascual-Leone, J.A. (in press). An 'interteaching' informed approach to instructing large undergraduate classes. Journal of the Scholarship of Teaching and Learning.

\section{Biographies}

Alan Scoboria is an Associate Professor of Psychology at the University of Windsor, Ontario. His scholarly interests include memory accuracy, metacognition, false memory, and best practices in clinical and forensic interviewing.

Fuschia Sirois is an Associate Professor in the area of Applied Social Psychology at the University of Windsor, Ontario. Her research interests outside of interteaching are in the area of health psychology; she has co-authored a Canadian textbook on this topic.
Antonio Pascual-Leone is an Assistant Professor and clinical psychologist at the University of Windsor, Ontario. His scholarly interests centre around the study of emotion and psychotherapy, and a special interest in teaching psychotherapy skills to graduates and undergraduates. 